\title{
STUDI OPERASI RESIN PENUKAR ION DALAM SISTEM PURIFIKASI AIR PRIMER PWR
}

\author{
Dwi Biyantoro, Kris Tri Basuki, R. Subagiono \\ PTAPB - BATAN
}

\begin{abstract}
ABSTRAK
STUDI OPERASI RESIN PENUKAR ION DALAM SISTEM PURIFIKASI AIR PRIMER PWR. Telah dilakukan studi operasi resin penukar ion dalam sistem purifikasi air primer PWR. Air pendingin reaktor yang pada awalnya sesuai dengan persyaratan setelah pengoperasian reaktor sering kualitasnya berubah, sehingga harus dimurnikan. Unsurunsur pengotor dalam air primer PWR diidentifikasi sebagai penyebab pengotor seperti korosi, pelepasan produk fisi $\left(\mathrm{Cs}^{137}, \mathrm{Sr}^{90}, \mathrm{Co}^{60}, \mathrm{C}^{14}, T \mathrm{C}^{99}\right)$, dan pelepasan kembali unsur oleh resin penukar ion. Air yang sudah tidak sesuai dengan persyaratan reaktor kemudian dilakukan pemurnian mengunakan resin penukar ion. Resin-resin ini digunakan untuk menghilangkan kotoran yang tidak diinginkan, seperti material-material radioaktif atau pencemaran yang lain yang dapat secara potensial merugikan peralatan atau merusak bahan bakar reaktor. Resin-resin penukar ion yang direkomendasikan digunakan dalam reaktor PWR (komersial) untuk purifikasi adalah sebagai berikut: penukarpenukar kation : Resin IRC-50, Resin 200-H, dan Resin 650-C, penukar-penukar anion : Resin A-550 dan Resin 900$\mathrm{OH}$, dan penukar campuran : Resin 21H (ECODEX P-202-H). Resin penukar ion tersebut adalah termasuk polimer organik sintetis yang mempunyai matriks/network yang berupa polistiren (PS) dan pengikat silangnya divinil benzen (DVB). Resin polistiren - divinilbenzen (PSDVB) mempunyai sifat-sifat yang menguntungkan sebagai penukar ion seperti kapasitas penukaran yang baik, selektif, ukuran partikel dengan ukuran tertentu, kestabilan resin tinggi pada berbagai $\mathrm{pH}$, laju pertukaran ion yang cepat, dan limbah yang dihasilkan relatif kecil.
\end{abstract}

\begin{abstract}
STUDY ON THE OPERATION OF ION EXCHANGE RESIN IN THE PURIFICATION SYSTEM OF PWR PRIMARY WATER. Study on the operation of ion exchange resin in the purification system of PWR primary water has been done. Reactor cooling water, which in the beginning a stable with the required condition, but after reactor operation its quality often changes so it must be purified. Impurity substances in PWR primary water are corrosion, the radioactive contaminants of fission product $\left(\mathrm{Cs}^{137}, \mathrm{Sr}^{90}, \mathrm{CO}^{60}, \mathrm{C}^{14}, \mathrm{TC}^{99}\right)$ and the leached from ion exchange resins. Water which is not satisfied for operation must be purified using ion exchange resins. The resins used to remove unwanted impurities, such as radioactive materials or other contaminants that could potentially harm the equipment or corrode reactor fuel rods. Resins which are recommended used in PWR (commercial) purification were as follow : cation exchanges IRC-50, 200-H, and 650-C, anion exchanges A-550 and 900-OH, mixture of cation and anion exchange was $21 \mathrm{H}$ (Ecodex $P$-202-H). Those ion exchange resins are synthetic organic polymer having matrix polystyrene (PS) and cross linking divinylbenzene (DVB). As an ion exchanges, resin of polystyrene - divinylbenzene (PSDVB) has an advantage properties such as good exchange capacity, selectivity, particle size compatibility, high stability at $\mathrm{pH}$ condition, fast flow rate of ion exchange, and the least waste volume produced.
\end{abstract}

\section{PENDAHULUAN}

$\mathrm{A}$ ir pendingin primer berfungsi untuk memindahkan panas yang timbul di teras reaktor, sebagai moderator dan sebagai perisai radiasi. Pengelolaan air pendingin primer bertujuan untuk menjaga agar spesifikasi kualitas air pendingin primer tetap terjaga. Metode pengelolaannya yaitu dengan cara pemantauan secara rutin seminggu sekali terhadap $\mathrm{pH}$, konduktivitas air pendingin primer dan perlakuan kimiawi yang berupa penggantian resin penukar ion pada sistem purifikasi.

Untuk menghilangkan hasil aktivasi dan kotoran mekanik air pendingin primer dan menjaga kualitas air pendingin primer pada tingkat yang diizinkan maka pada sistem pendingin primer dilengkapi dengan sistem purifikasi (pemurnian). 
Sistem purifikasi terdiri dari sistem filter mekanis dan beberapa kolom resin penukar ion. Dengan bertambahnya waktu penggunaan resin tersebut akan mengalami kejenuhan. Untuk mengetahui kejenuhan resin penukar ion perlu dilakukan pengukuran kualitas air pendingin primer sebelum dan sesudah melewati resin. Apabila resin penukar ion tersebut sudah jenuh, maka perlu diganti resin baru dan tidak dilakukan regenerasi. Hal ini dikarenakan resin yang telah digunakan akan menjadi aktif.

Industri nuklir komersial (PWR) memanfaatkan resin pertukaran ion untuk proses menjernihkan air. Resinresin ini digunakan untuk menghilangkan kotoran yang tidak diinginkan, seperti material-material radioaktif atau pencemaran yang lain yang dapat secara potensial merugikan peralatan atau merusak reaktor fuel rods. Resin pertukaran ion digunakan dalam beberapa proses untuk menghilangkan resiko dan unsur pokok radioaktif dari kotoran dan larutan. Dalam fasilitas reaksi, resin pertukaran ion digunakan untuk membersihkan air di kolam reaksi dan kolam penyimpanan bahan bakar.

Beberapa kontaminan radioaktif yang timbul diantaranya $\mathrm{Cs}^{137}, \mathrm{Sr}^{90}, \mathrm{Co}^{60}, \mathrm{C}^{14}$, dan $\mathrm{Tc}^{99}$. Di Amerika Serikat dalam setahun, reaktor komersial menghasilkan limbah resin kira-kira 100.000 lbs untuk BWR dan 30.000 Ibs untuk PWR.

\section{PEMANTAUAN KUALITAS AIR PENDINGIN REAKTOR}

Salah satu cara pemantauan kualitas air pendingin primer dan air bebas mineral dapat dilakukan dengan mengukur $\mathrm{pH}$ dan konduktivitas. Pengukuran $\mathrm{pH}$ dan konduktivitas pada air pendingin primer dilakukan sebelum dan sesudah melewati resin penukar ion pada sistem pemurnian air. Dari pemantauan terhadap kualitas air pendingin primer terlihat adanya data yang bervariasi dan adanya perbedaan spesifikasi air pendingin primer antara sebelum dan sesudah melewati resin penukar ion. Hal ini disebabkan resin penukar ion mampu mengikat ion logam yang terkandung dalam air pendingin. Dengan bertambahnya waktu penggunaan resin penukar ion pada sistem pemurnian maka resin penukar ion tersebut akan mengalami kejenuhan sehingga perlu diganti dengan resin baru dan tidak dilakukan regenerasi.

Pengendalian air pendingin primer berguna untuk pengendalian korosi pada komponen reaktor dan tangki bahan bakar hingga dapat mengontrol reaktivitas nuklir, mereduksi sumber radiasi serta untuk memonitor integritas bahan bakar.

Tabel 1. Spesifikasi air pendingin primer PWR-Jepang ${ }^{[4]}$

\begin{tabular}{|l|l|l|}
\hline \multicolumn{1}{|c|}{ Parameter } & Harga standar & Harga batas \\
\hline Boron (ppm) & $0-4000$ & \\
Klorida (ppm) & $\leq 0,05$ & $\leq 0,15$ \\
Fluorida (ppm) & $\geq 0,05$ & $\geq 0,15$ \\
Oksigen terlarut & $\leq 0,005$ & $\leq 0,1$ \\
Hidrogen terlarut (ml/Kg- $\mathrm{H}_{2} \mathrm{O}$ & $25-35$ & $15 \leq \mathrm{x} \leq 50$ \\
Litium (ppm) & $0,2-2,2$ & 3,5 \\
Turbiditas (NTU) & $\leq 1,0$ & \\
\hline
\end{tabular}

Oleh sebab itu air yang digunakan sebagai air pendingin reaktor nuklir harus memenuhi persyaratan yang sesuai dengan reaktor tersebut. Pemahaman kimia air khususnya mengenai studi operasi resin penukar ion dalam sistem purifikasi air primer PWR menjadi sangat penting.

Kontrol kimia, purifikasi dan makeup

- Kontrol pH dengan lithium hydroksida (LiOH)

- Kontrol konsentrasi oksigen dengan hidrasin

- Purifikasi untuk memisahkan korosi dan produk fisi dengan mixed bed demineralisasi / pertukaran ion

- Kontrol boron sebagai absorbsi netron dan makeup volume. 


\section{PROSES PENGOLAHAN}

Proses penukar ion dimaksudkan untuk menukar kation yang ada dengan ion $\mathrm{H}$ dan semua ion yang ada dengan ion $\mathrm{OH}$. Misal suatu resin penukar ion yang mempunyai counter ion $\mathrm{A}^{+}$yang dapat di pertukarkan, dikontakkan dengan larutan yang mengandung ion $\mathrm{B}^{+}$. Reaksi pertukaran yang berlangsung adalah sebagai berikut

$$
\begin{aligned}
& \mathrm{R}_{\text {(resin) }} \mathrm{A}^{+}+\mathrm{B}_{\text {(larutan) }}^{+} \quad 9 \quad \mathrm{R}_{\text {(resin) }}^{-} \mathrm{B}^{+}+\mathrm{A}_{\text {(larutan) }}^{+} \\
& \mathrm{R}^{-} \text {: gugus ionogenik resin } \\
& \mathrm{A}^{+} \text {: counter ion }
\end{aligned}
$$

Keseimbangan pertukaran tercapai jika konsentrasi ion dalam resin sama dengan konsentrasi ion dalam larutan.

Cation exchange resin $(\mathrm{R}-\mathrm{H})$ dan anion exchange resin $(\mathrm{R}-\mathrm{OH})$ dimasukkan dalam mixed bed polisher. Pada saat air yang berisi ion-ion melewati resin terjadi reaksi beriku :

Sebagai contoh :

$$
\begin{aligned}
& \mathrm{R}-\mathrm{H}+\mathrm{NaCl} \rightarrow \mathrm{R}-\mathrm{Cl}+\mathrm{HCl} \\
& \mathrm{R}-\mathrm{OH}+\mathrm{HCl} \rightarrow \mathrm{R}-\mathrm{Cl}+\mathrm{H}_{2} \mathrm{O}
\end{aligned}
$$

Mutu air bebas ion dimonitor dengan mengukur hantaran listriknya.

Jika semua proses ini berjalan ideal maka akan diperoleh air yang bebas mineral dan bebas pengotor, walaupun kenyataannya tidak seperti itu, pengotor dalam batas yang diijinkan akan tetap ada. Air yang sudah diproses kemudian digunakan sebagai air tangki reaktor.

Pengotor yang terjadi akibat dari pengoperasian reaktor antara lain :

- Pengotor karena proses korosi pada dinding reaktor dan sistem pendingin primer serta komponen yang ada pada reaktor.

- Pengotor karena produk fisi $\left(\mathrm{Cs}^{137}, \mathrm{Sr}^{90}, \mathrm{Co}^{60}, \mathrm{C}^{14}\right.$, dan $\left.\mathrm{TC}^{99}\right)$

Air yang digunakan sebagai pendingin mempunyai persyaratan (spesifikasi kualitas air) yang sesuai dengan komponen atau struktur reaktor tersebut. Untuk menjaga air supaya tetap berfungsi sebagai air pendingin primer, maka dilakukan proses purifikasi menggunakan resin penukar ion pada air yang sudah terkontaminasi.

Pada sistem pendingin primer, air pendingin secara kontinyu dilewatkan pada suatu sistem purifikasi yang terdiri dari filter mekanis dan kolam penukar ion yang berfungsi untuk menjaga agar spesifikasi kualitas air pendingin primer tetap terjaga. Metode pengelolaan dengan cara pemantauan rutin seminggu sekali terhadap $\mathrm{pH}$, konduktivitas air pendingin primer dan perlakuan kimiawi berupa penggantian resin penukar ion pada sistem purifikasi.

Resin-resin yang direkomendasikan digunakan dalam reaktor PWR (komersial) adalah sebagai berikut: A-550, IRC-50, 2IH, 900-OH, 200-H dan 650-C. Keenam resin ini diperoleh dengan mempertimbangkan representatif dari resin pertukaranan ion yang digunakan oleh industri nuklir komersial. Resin-resin ini mempunyai komposisi kimia yang stabil dan tahan panas.

Bahan penukar ion yang banyak digunakan adalah polimer organik sintetis yang mempunyai matriks/network yang berupa polistiren (PS) dan pengikat silangnya divinil benzen (DVB). Gugus ini dapat mengalami ionisasi menjadi ion-ion yang terikat secara tetap pada matriks (gugus-gugus ionogenik) dan counter ion-ion mobil yang bermuatan berlawanan yang dapat dipertukarkan. Bergantung pada jenis penukar ionnya, gugus-gugus ionogenik dapat bermuatan positif atau negatif.

\section{Jenis resin yang dapat digunakan dalam sistem purifikasi air primer PWR}

Dalam industri nuklir (PWR), resin penukar ion digunakan untuk pemurnian air pendingin primer. Pemilihan resin yang digunakan dalam sistem purifikasi air primer PWR senantiasa memperhatikan berbagai segi antara lain : harga, spesifikasi, karakteristik, kemampuan untuk memisahkan material radioaktif, limbah yang dihasilkan dan pencemaran yang lain. Ada enam resin yang dapat digunakan dalam sistem purifikasi air primer PWR, yaitu : A-550, IRC-50, 2IH, 900-OH, 200-H, dan 650-C 


\section{Resin A-550}

Resin A-550 adalah jenis resin pertukaran anion dalam bentuk gel yang sangat kuat termasuk group polystyrene divenylbenzene. Sifat tipe resin termuat dalam Tabel 2.

Tabel 2. Sifat Resin Pertukaran Ion A-550

\begin{tabular}{|l|c|}
\hline \multicolumn{1}{|c|}{ Bentuk lon } & $\mathrm{Cl}$ \\
\hline \hline Group Aktif & Amina Kuartener Tipe II Alkil \\
\hline Matrik & Polistiren \\
\hline Struktur & Gellular \\
\hline
\end{tabular}

\section{Resin IRC-50}

Resin IRC-50 adalah resin pertkran ion asam lemah. Resin ini diproduksi dibawah merk dagang amberlit, digunakan untuk dealkalization atau demineralization. Komposisi kira-kira $47 \%-53 \%$ divenylbenzene dan $47-$ $53 \%$ air. Sifat fisika resin IRC-50 ditunjukkan dalam Tabel 3.

Tabel 3. Sifat Resin Pertukaran Ion IRC-50

\begin{tabular}{|l|c|}
\hline \multicolumn{1}{|c|}{ Bentuk Ion } & $\mathrm{H}$ \\
\hline \hline Group Aktif & Asam karboksilat \\
\hline Matrik & Polistiren \\
\hline Struktur & Beads \\
\hline Minimum Capacity & $4.2 \mathrm{eq} / \mathrm{L}$ \\
\hline pH range & $5-7$ \\
\hline
\end{tabular}

\section{Resin 21H}

Resin $21 \mathrm{H}$ adalah jenis resin pertukaran kation yang bercampur dengan fiber selulosa, dimana resin bentuk ion $\mathrm{H} / \mathrm{OH}$ bercampur dengan kira-kira 1/3 fiber cellulose. Sifat fisika resin $21 \mathrm{H}$ ditunjukkan dalam Tabel 4.

Tabel 4. Sifat Resin Pertukaran Ion ECODEX P-202-H

\begin{tabular}{|l|c|}
\hline Bentuk lon & $\mathrm{H} / \mathrm{OH}$ \\
\hline \hline Group Aktif & Asam karboksilat \\
\hline Matrik & Polistiren/Selulosa \\
\hline Struktur & Powder \\
\hline
\end{tabular}

\section{Resin 900-OH}

Tabel 5. Sifat Resin Pertukaran lon 900-OH

\begin{tabular}{|l|c|}
\hline \multicolumn{1}{|c|}{ Bentuk Ion } & $\mathrm{OH}$ \\
\hline \hline Group Aktif & Amina Kuartener Tipe II Alkil \\
\hline Matrik & Polistirene \\
\hline Struktur & Macroreticular \\
\hline Kapasitas Minimum & $0.90 \mathrm{eq} / \mathrm{L}$ \\
\hline Temp. Dekomposisi & $140^{\circ} \mathrm{F}$ \\
\hline
\end{tabular}

Resin $900-\mathrm{OH}$ adalah resin anion styrene divenylbenzene dasar kuat. Diproduksi dibawah merk dagang Ambersep dan secara normal digunakan untuk aplikasi kondensor. Komposisinya kira-kira $35-55 \%$ quaternary amine divenylbenzene bersifat $\mathrm{OH}$ dan $45-65 \%$ air. Sifat fisika ditunjukkan dalam Tabel 5. 


\section{Resin 200-H}

Resin $200-\mathrm{H}$ adalah resin kation styrene/divenylbenzene sulfonat asam kuat. Sifat fisika ditunjukkan dalam Tabel 6.

Tabel 6. Sifat Resin Pertukaran lon 200-H

\begin{tabular}{|l|c|}
\hline \multicolumn{1}{|c|}{ Bentuk Ion } & $\mathrm{H}$ \\
\hline \hline Group Aktif & Asam Sulphonik \\
\hline Matrik & Polistiren \\
\hline Struktur & Macroreticular \\
\hline Kapasitas Minimum & $1.70 \mathrm{eq} / \mathrm{L}$ \\
\hline Temp. Dekomposisi & $300^{\circ} \mathrm{F}$ \\
\hline
\end{tabular}

\section{Resin 650-C}

Resin 650-C adalah resin kation styrene/divinylbenzene sulfonat asam kuat. Komposisinya kira-kira $47-53 \%$ divinylbenzene dan $47-53 \%$ air. Sifat fisika ditunjukkan dalam Tabel 7.

Tabel 7. Sifat Resin Pertukaran Ion 650-C

\begin{tabular}{|l|c|}
\hline Bentuk Ion & $H$ \\
\hline \hline Group Aktif & Asam Sulphonik \\
\hline Matrik & Polistiren \\
\hline Struktur & Macroreticular \\
\hline
\end{tabular}

Pendingin primer reaktor memerlukan kemurnian air yang tinggi, hal ini diperlukan untuk menekan proses deposisi kelongsong elemen bakar yang panas serta korosi berbagai komponen reaktor yang terbuat dari bahan logam, khususnya aluminium. Air pendingin primer berfungsi untuk memindahkan panas yang timbul akibat reaksi fisi, dimana air tersebut berhubungan langsung dengan kelongsong elemen bahan bakar dan berbagai komponen reaktor lainnya yang berada di teras reaktor.

Air pendingin primer harus mempunyai tingkat kemurnian yang tinggi agar tidak terkontaminasi hasil reaksi fisi sehingga sifat keradioaktifan hilang atau dapat ditekan akibat paparan netron. Kemurnian yang tinggi tersebut sangat diperlukan untuk menekan proses deposisi kelongsong elemen bakar yang panas serta korosi berbagai komponen, akibat berbagai komponen reaktor umumnya terbuat dari logam (terutama Al). Sehingga air yang digunakan untuk pendingin primer harus memenuhi persyaratan analisis keselamatan sebagaimana tercantum dalam Tabel 1.

Sifat pendingin reaktor antara lain :

1. Reaktor jenis air ringan, air digunakan sebagai zat pendingin serta pengendali reaktivitas reaktor (moderator).

2. Pendingin air di dalam reaktor akan mengalami tekanan serta suhu yang relatif tinggi.

3. Pendingin menjadi bersifat reaktif terhadap bahan kelongsong dan bahan struktur.

4. Teras terkena radiasi sinar pengion bertenaga tinggi sehingga dapat terjadi ionisasi dan pemutusan ikatan kimia.

5. Kemungkinan dapat terjadi keretakan kelongsong bahan bakar hingga terjadi difusi gas hasil belah yang menyebabkan kontaminasi.

Syarat-syarat pendingin reaktor :

1. Mempunyai kestabilan kimia yang cukup tinggi, walaupun berada di sekitar reaksi inti.

2. Mempunyai kapasitas panas dan hantaran panas yang tinggi.

3. Tidak bersifat korosif terhadap bahan struktur reaktor dan kelongsong bahan bakar.

4. Mempunyai tampang serapan netron yang kecil. 


\section{Aktivasi dan kontaminasi air pendingin}

Kontaminasi air pendingin terdiri dari :

1. Radioaktivitas yang berasal dari air itu sendiri

2. Radioaktivitas yang berasal dari aktivasi bahan kelongsong dan struktur reaktor yang terkorosi

3. Radioaktivitas yang berasal dari kontaminasi hasil belah

Solusi untuk kontaminasi air pendingin primer adalah sebagai berikut :

1. Monitoring $\mathrm{pH}$, konduktivitas dan kandungan unsur-unsur kimia seperti : $\mathrm{Al}, \mathrm{Cu}, \mathrm{Si}, \mathrm{Cl}$, dan $\mathrm{CO}_{3}$. Unsur-unsur ini dapat mengakibatkan korosi baik pada kelongsong maupun bahan struktur (tangki) terutama pada sambungan.

2. Monotoring radioaktivitas dari Na-24. Radioaktivitas Na-24 biasanya konstan, sehingga apabila terjadi kenaikan dapat digunakan sebagai indikator adanya kenaikan korosi pada bahan kelongsong maupun bahan struktur yang terbuat dari paduan logam aluminium.

3. Sirkulasi air pendingin melewati resin penukar ion yang terdiri dari penukar anion dan kation (mixed bed resin) agar unsur-unsur kelumit yang teraktivasi maupun produk korosinya terikat pada resin tersebut.

Akibat operasi reaktor pada suhu dan tekanan cukup tinggi maka sebagian kecil dari hasil korosi tersebut akan larut dalam air pendingin dan akan memberikan sumbangan terhadap radioactivitas.

Agar spesifikasi kualitas air pendingin tetap terjaga, dilakukan pengelolaan air pendingin yang berupa pemantauan secara rutin dan adanya perlakuan baik secara mekanis maupun dengan menambahkan bahan kimia tertentu. Air pendingin primer secara kontinyu dilewatkan pada suatu sistem purifikasi yang terdiri dari filter mekanis dan kolom penukar ion.

Reaksi pertukaran yang terjadi :

$$
\mathrm{H}^{+}+\mathrm{OH}^{-} \rightarrow \mathrm{H}_{2} \mathrm{O}
$$

Mutu air bebas ion dimonitor dengan mengukur konduktivitas listriknya.

Pada sistem terdiri mix-bed filter dan filter mekanik serta resin penukar ion yang berisi campuran anion $\mathrm{OH}^{-}$ tipe Lewatit $\mathrm{M} 500 \mathrm{KR} / \mathrm{OH}^{-}$dan kation $\mathrm{H}^{+}$resin tipe Lewatit $\mathrm{S} 100 \mathrm{KR} / \mathrm{H}^{+}$. Filter mekanik berupa resin trap yang dirancang dapat dibuka dan ditutup dari jarak jauh, untuk menghindari paparan radiasi yang timbul dari resin trap ini sebagai indikasi penggantian resin mix-bed filter adalah apabila beda tekanan antara sebelum dan sesudah melewati resin $>1,5$ bar. Sedangkan resin trap akan diganti jika perbedaan tekanan $>2$ bar.

\section{PEMURNIAN (PURIFIKASI)}

Jika resin di masukkan ke dalam air, maka air akan terserap resin dan resin akan menggelembung, sedangkan gugus asamnya larut. Besarnya penggelembungan resin ditentukan oleh derajad ikatan silangnya, yaitu banyaknya \% berat divinilbenzen dalam resin. Semakin besar derajad ikatan silangnya akan semakin kuat ikatan resin dan semakin kecil penggelembungannya. Resin yang dimasukkan dalam air akan terionisasi menurut persamaan :

$$
\text { Resin- } \mathrm{SO}_{3} \mathrm{H} \rightarrow \text { Resin- } \mathrm{SO}_{3}{ }^{-}+\mathrm{H}^{+}
$$

Ion $\mathrm{H}^{+}$dalam gugus sulfonat dapat diganti oleh kation yang lain $\left(\mathrm{Cs}^{137}, \mathrm{Sr}^{90}, \mathrm{Co}^{60}, \mathrm{C}^{14}\right.$, dan $\left.\mathrm{Tc}^{99}\right)$. Reaksi pertukaran kation ini akan sangat tergantung pada afinitas kation terhadap gugus fungsi sulfonat. Afinitas atau kekuatan ikatan suatu kation pada gugus sulfonat akan sangat tergantung pada muatan kation dan jari-jari ion.

Penukar ion organik mempunyai network/matriks yang berupa polimer sintetis (resin) dengan gugus-gugus fungsi yang terikat secara kimia pada metrik polimer. Penukar ion yang paling penting dan banyak digunakan adalah suatu resin yang merupakan polimer-polimer organik dengan gugus-gugus ionogenik yang hidrofilik diikutsertakan di dalamnya. Resin organik yang banyak digunakan adalah resin polistiren - divinilbenzen (PSDVB), suatu resin penukar ion yang mempunyai ikatan silang (cross linking) dan mempunyai sifat-sifat yang hampir ideal 
sebagai resin penukar ion. Stiren mempunyai rumus kimia $\left(\mathrm{C}_{6} \mathrm{H}_{5} \mathrm{CH}=\mathrm{CH}_{2}\right)$, polistiren $\left(\left(\mathrm{C}_{6} \mathrm{H}_{5} \mathrm{CH}=\mathrm{CH}_{2}\right)_{n}\right)$, dan rumus kimia divinilbenzena (DVB) $\left(\mathrm{C}_{6} \mathrm{H}_{4}\left(\mathrm{CH}=\mathrm{CH}_{2}\right)_{2}\right)$.

Resin polistiren - divinilbenzen (PSDVB) mempunyai sifat-sifat yang mengun-tungkan sebagai penukar ion karena mempunyai kapasitas penukaran yang baik, selectivitas/afinitas terhadap jenis kation/anion yang berbeda, kisaran $\mathrm{pH}$ ionisasi gugus ionik, ukuran partikel dengan ukuran tertentu, kestabilan resin tinggi pada kondisi berbagai $\mathrm{pH}$, kestabilan fisik yang cukup baik pada tekanan tinggi, laju pertukaran yang cepat, dan limbah yang dihasilkan relatif kecil.

Proses purifikasi dikerjakan dengan cara air pendingin primer dialirkan melalui heat exchanger, melewati mixed bed demineralizer dan filter pendingin, selanjutnya menuju tangki control volum.

\section{Kolom penukar ion}

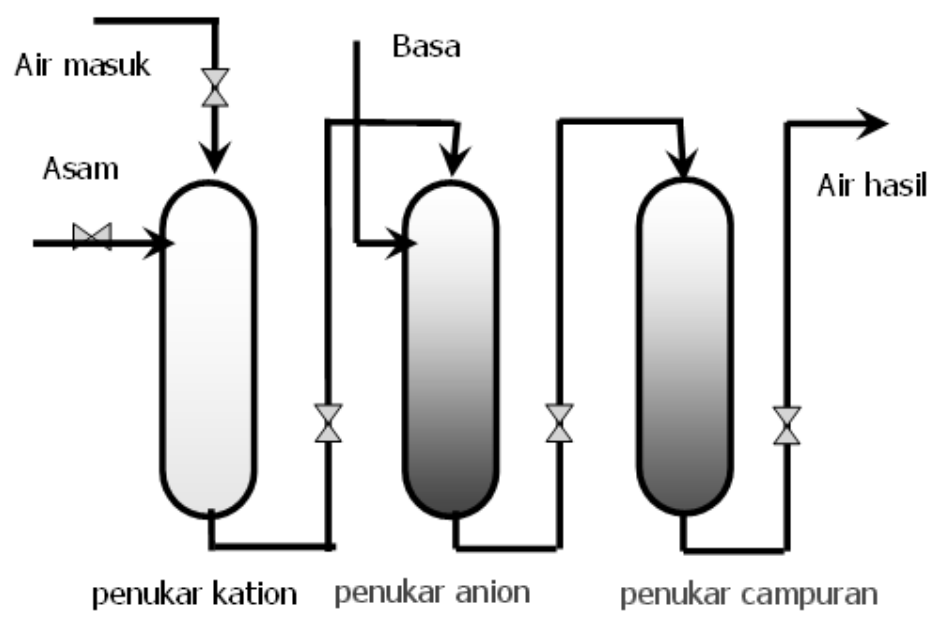

Gambar 1. Skema kolom penukar ion

\section{Operasi resin penukar ion dalam sistem purifikasi air primer PWR :}

Untuk operasi resin penukar ion yang direkomendasikan dalam sistem purifikasi air primer PWR adalah sebagai berikut :

\section{Penukar kation}

Jenis resin yang dapat digunakan yaitu : Resin IRC-50, Resin 200-H, dan Resin 650-C.

\section{Penukar anion}

Jenis resin yang dapat digunakan yaitu : Resin A-550 dan Resin 900-OH.

Penukar campuran

Jenis resin yang dapat digunakan yaitu : Resin 21H (ECODEX P-202-H).

Resin penukar ion ini adalah polimer organik sintetis mempunyai matriks/network yang berupa polistiren (PS) dan pengikat silangnya divinil benzen (DVB).

\section{KETAHANAN POLIMER TERHADAP RADIASI.}

\section{Kestabilan fisika-kimia}

Kemampuan mempertahankan sifat fisika awal dan struktur kimia (makro dan mikro)

\section{Serviceability:}

Mampu berfungsi normal dalam medan radiasi 


\section{KESIMPULAN}

Pada operasi resin penukar ion dalam sistem purifikasi air primer PWR dapat disimpulkan bahwa air primer reaktor merupakan bagian yang penting dalam sistem reaktor, karena berfungsi sebagai pendingin, moderator, dan pelindung radiasi. Karena berbagai peristiwa air reaktor yang pada awalnya sesuai dengan persyaratan setelah pengoperasian reaktor sering kualitasnya berubah, sehingga harus dimurnikan kembali menggunakan resin penukar ion. Resin penukar ion yang direkomendasikan dipakai untuk purifikasi sebagai berikut :

a. Penukar kation digunakan yaitu : Resin IRC-50, Resin 200-H, dan Resin 650-C.

b. Penukar anion digunakan yaitu : Resin A-550 dan Resin 900- OH.

c. Penukar campuran digunakan yaitu : Resin $21 \mathrm{H}$ (ECODEX P-202-H).

Resin penukar ion yang banyak digunakan adalah polimer organik sintetis mempunyai matriks/network yang berupa polistiren (PS) dan pengikat silangnya divinil benzen (DVB). Resin polistirena - divinilbenzen (PSDVB) mempunyai sifat-sifat yang menguntungkan sebagai penukar ion karena mempunyai kapasitas penukaran yang baik, selektivitas/afinitas terhadap jenis kation/anion yang berbeda, kisaran $\mathrm{pH}$ ionisasi gugus ionik, ukuran partikel dengan ukuran tertentu, kestabilan resin tinggi pada berbagai $\mathrm{pH}$, kestabilan fisik yang cukup bila diperlukan tekanan tinggi, laju pertukaran yang cepat, dan limbah yang dihasilkan relatif kecil.

\section{UCAPAN TERIMA KASIH}

Pada kesempatan ini penulis mengucapkan banyak terima kasih kepada Prof. Y.Sarjono, Dr. Ir. Arnold Y.Sutrisnanto, dan Drs. Sumijanto yang telah memberi masukan dan pinjaman pustaka.

\section{DAFTAR PUSTAKA}

1. SCHLICHTER, B., MARVOV, V., CHMIEL, H., "Study of Hybride Process Combining Ozonation and Microfiltration/ultrafiltraton for Drinking Water Production From Survace Water", Institute For Environmentallly Compatible Process Technology Ltd., Departemen of Process Technology, Saarland University, Im Stadwald Geb. Saarbricken, Germany, (2004).

2. KUPITZ, J. AND MISRA, B. M., "The Role of Nuclear Desalination in Meeting the Potable Water Needs in Water Scarce in the next Decades", International Atomic Energy Agency (IAEA), Viena, Austria (2004).

3. SUTJIPTO, KRIS TRI BASUKI DAN SUKARMAN A., "Konsep Usulan Untuk Solusi Problem-problem Reaktor Triga 2000 dan Analisisnya" Disampaikan pada diskusi program Kimia Air dalam pemeliharaan komponen internalreaktor penelitian di P2TKN-BATAN, (22 Agustus 2000).

4. DIYAH, E. L., ALIM TARIGAN, AEP SAEPUDIN, C., "Pengolahan Kimia Air Pendingin Reaktor Serbaguna G.A. Siwabessy", Disampaikan pada diskusi Kimia Air dan Reaktor di P3TN-BATAN Bandung, 27 Juli 2000.

5. IAEA, "Water Chemistry and Corrosion Problems in Nuclear Power Plants", Proceedings of a symposium , Vienna , (22 - 26 November 1982).

6. RAINWATER J.H. , "Maintainance of Primary Coolant Water Quality in The Material Testing Reactor" Phillips Petrolium Co , Idaho Operation Office , USAEC , (1957).

7. K.O.R. , "Spectrochemical Analysis of Water", Hanford Atomic Products Operation "Washington, (1957).

8. HARTOMO, A. J. AND WIDIATMOKO, M. C., Teknologi Membran Pemurnian Air, Andi Offset, Yogyakarta, (1994).

9. ASIJATI, E, National Training Course on Water Chemistry of Nuclear Reactor System, Jakarta, (2004).

10. NACHOD, F. C. AND SCHUBERT, J., Ion Exchange Technology, Academic Press Inc., Publishers, New York, (1954). 